\title{
Financing Secondary Education in Kenya: Exploring Strategic Management Approach for Improving Quality of Education
}

\author{
Florence M. Itegi \\ School of Education, Kenyatta University Kenya, Nairobi
}

Copyright $(2016$ by authors, all rights reserved. Authors agree that this article remains permanently open access under the terms of the Creative Commons Attribution License 4.0 International License

\begin{abstract}
The aim of this paper is to explore the influence of strategic planning in improving the quality of education. The quality of education is directly linked to the effort expended in making arrangements or preparations of educational objectives and determining the requisite resources to facilitate the training, instruction or study that leads to the acquisition of skills or knowledge. Education at secondary sector is of particular importance because it seeks to augment the general intellectual skills acquired at primary level, which are also relevant to any productive occupation including subsequent education. In Kenya, the Decentralized Education Management Activity initiated by the Ministry of Education in 2012 in partnership with USAID embarked on capacity development among education managers at the district and school level to enable them prepare and implement strategic plans. This notwithstanding, education at secondary level continues to experience unique challenges which are more often attributed to deficiencies in planning. Lack of emphasis on careful planning and implementation of plans could have implications for institutions in the current competitive environment. This paper is based on literature search on educational administrators' perceptions of strategic plans, formulation, implementation and their effects on the quality of education. From literature, the vital role of strategic planning in enhancing quality of education is underscored; evidently, some schools have strategic plans in spite of the constraints in their formulation. Strategic planning is viewed as a tool that enables stakeholders to increasingly contribute to the school's strategic objectives which result in long-term sustainability and improvement in quality of education.
\end{abstract}

Keywords Strategic Planning, Secondary Education, Quality, Efficiency, Stakeholders Involvement and Sustainable Development

\section{Introduction}

No country can respond successfully to the need of increasing production in manufacturing and service industry without middle level workers who are likely to have benefited from secondary level education. This notwithstanding, in many developing countries, places in secondary schools are much more expensive than those at primary schools in an environment where external support for secondary education has been erratic. In the long term, possible solution may be significant cost reduction in school system associated strategic management. In this approach, public private partnerships and income generation to enhance effectiveness and efficiency will become more attractive policy options. In Kenya, differential growth among secondary schools is already manifest based on varied management approaches. Schools that have adopted strategic management approaches offer access to quality education, infrastructural support for learning and better human resources.

The purpose of this article is to explore the influence of strategic planning on quality of education in secondary schools. Strategic planning is the tool for establishing institutional framework to enhance involvement and cooperation among all relevant players at the local, national and international levels. It's a process by which organizations determines what to focus on in a specified period. Strategic planning helps the management to predict future conditions and realities, internal and external that affects their projections. Strategic management approach generates work plans, objectives, tasks, procedures, responsibilities or groups or individuals and timelines for activities. The organization management is able to determine priorities and operations necessary to achieve the organizational vision.

During the past two decades, attention has focused on primary level education especially in relation to girls' education. This has led to neglect of secondary and higher education in most developing countries, which are 
underfunded by both governments and donors. In Kenya, the launch of Free Primary Education in 2003 mounted pressure on the secondary sector in the year 2012. At this period, a large number of graduates of Free Primary Education could not be accommodate in existing secondary schools forcing the government to extend subsidy to secondary sector in form of Free Day Secondary Education [1]. In the year $2013 / 2014$, education sector in Kenya allocated $18 \%$ of the total national budget out of which $7.5 \%$ was allocated to Free Day Secondary. This is a clear indication that expansion of secondary education has been a longstanding objective of the Kenyan government in line with Education for all goals. This notwithstanding, it's not clear how prepared institutional management are to receive and expend this hefty share of resources in an effective and efficient manner [2].

The recent expansion of secondary education has produced consequences; existing institutions have grown in size; with new ones established amidst constrained resources. As a result, quality deterioration became eminent while access remains limited. In some schools, physical facilities are stretched several times the number they were originally set up for and were grossly inadequate [3]. The number of students in a class increased and nothing was done to ensure quality teaching [1]. Amidst these constraints evaluation continues to be through national examinations and teachers are under pressure to produce good grades. Quality in education means meeting needs and exceeding the expectations of stakeholders, and continuous quality improvement requires consistency of purpose. Hence, strategic planning offers the most systematic, flexible and yet sustainable tool for quality improvement. Two greatest challenges for secondary education are to absorb growing number of students from expanded primary system and provide quality education to build on their basic knowledge and skills, broaden their competences and enhance the employment opportunities for graduates [4].

The gains in access to secondary education have also turned attention to the challenge of improving quality of education and accelerating learning. Improvement of access, retention and quality will depend on efficient use of existing resources and exploring alternative sources of income. Balanced investment strategies are needed to reconcile competing demands for public finance within the formal education sector [5]. Careful appraisal is needed in the light of changing domestic and international circumstances which recognize efficient management of public funds accompanied by entrepreneurial spirit for institutional sustainability and growth. Strategic planning has proved itself in making best use of scarce resources including infrastructure and human resources.

Strategic planning provides a framework for organizations to fulfill their mission in a more efficient and effective manner. It promotes monitoring whether plans are being achieved and realigning them with strategically agreed upon goals. If it is properly implemented and revised, strategic planning will enhance students' achievement. It's a participatory process that is transparent when anchored in the culture of the organization.

\section{Why Strategic Planning in Secondary Education Sub-sector?}

In Kenya, operations in the education sector are financed through public funds in form of taxes, payment of fees by parents or guardians, private firms or individuals and international donor agencies. The Kenyan government direct funds to schools through Free Primary Education grants (FPE), Free Day Secondary Funds (FSD), Constituency Development Funds (CDF) and the County Development Funds in devolved units. On the other hand, Parents meet direct cost including boarding fees, activity fees, uniforms, transportation and lunches. Indirect or opportunity costs include the household labour and income that could have been earned by children while in school. These justify the need for schools to respond to internal and external demand for accountability and transparency through developed standards for assessment of resource utilization and learning outcomes.

With the introduction of free and compulsory primary education, financial resources for support of schools are not likely to increase at the expected rate. Yet, the demand for secondary education continues to bulge. In Malawi, this mentality blend discord as school facilities continued to be dilapidated with roofs falling off, widows falling off, and flours with potholes [3]. This article argues that strategic planning comes in handy to minimize crisis management model of decision making by helping school management to establish alternative sources of resources to supplement government funding. Strategic planning is much more likely to result into deliberate shift of mission in the light of changes actual or anticipated. Strategic planning creates a document that can be used to seek partnerships and fundraising from well-wishers.

The push for schools to be run transparently and improve quality have seen schools examine their mission and vision, assess their current state, setting new goals, determining action plans to achieve set goals, and measure progress towards goals as characteristics of successful schools. This has culminated into a competitive environment where some schools have gained advantage over others with overwhelming number of students seeking admission in such schools. In such scenario, these schools admit students with higher grades who are focused and graduate with top class grades at the end of four years secondary cycle. It earns the school favor from the government, parents, donors and well-wishers who willingly provide resources to maintain state of the art facilities while some other schools struggle to offer the bare minimum facilities to support teaching and learning. In many developing countries like Kenya, the rich is more able to access expensive schools that produce best students who then dominate university education which is highly subsidized in public sector. Consequently, expenditures by the poor have been observed to be proportionately high as majority dominates the 
self-sponsored sector of higher education. This raises the need for accountability in the management of funds in the public sector and especially education which is a driver for social economic development of any nation [5].

As mass secondary education becomes a government and donor priority and more resources allocated to its expansion, development of Strategic plans as stronger accountability mechanism will be necessary to ensure efficient and effective use of available resources. In the past strategic planning has been viewed as appropriate for private schools. However, in this error of liberalized economies in many countries public institutions can no longer depend on government funding and donors to sustain their operations. Effective schools have been found to engage in income generating initiatives and were able to offer students and staff opportunities to learn by doing and sustain their operations through School Self-sufficient Model. A consideration should be given between building large schools that benefit from economies of scale but hard to reach and small schools that are accessible but possibly more expensive to run [3]. This means strategic planning has to be factored in at the ministerial level to avoid adhoc establishment of school as manifested in slums and rural regions of Kenya without proper planning. Education authorities should provide leadership in providing information on designated school sites based on school going population to avoid duplication of efforts.

The most important factors in determining effective schools are quality and relevance of teaching and learning. To improve quality of education, planning must focus on teaching and learning, student service such as guidance and counseling, sufficient infrastructure including laboratories, electricity, water and sanitary facilities which provide favorable environment for learning and teacher support system. Every student can achieve high standards of learning and public schools are the foundation of good citizenship. Strategic planning promotes responsible stewardship of resources, professional collaboration and preparing students for success beyond high school. Strategic planning factors in, income generating projects help schools to run more economically. Such schools could provide education to even poorest students without relying on government support or charging students from poor background fees [6].

Strategic planning that has been found to enhance expansion of schools and accountability is significantly increased bringing improved and modern management styles in addition to performance based monitoring. Strategic management approach helps the organization to remain relevant, responsive to the needs of its community and contributes to organizational stability and growth. It provides basis for monitoring progress and assessing results. Strategic planning enables the school management to set priorities and goals to guide its operations and get a clear focus for strategy implementation. Through strategic planning, the organization is able to define its vision for future, determine how it will get there, and understand the obstacles and how to overcome them. The strategy is associated with financial management with the main goal as to determine availability of funds to sustain daily needs and investment purpose; earning maximum return on cash invested and; protect assets of the school against loss.

In Kenya, like many other developing countries, secondary schools have weak management, problems of discipline associated with constrained resources, mismanagement of resources due to unethical dealings and cases of schools operating on annual budgets with minimal or no development abound. The process of selecting students to join secondary schools makes education an obstacle race by setting barriers where persons considered incapable are shut out. Primary schools have to continue with the pressure generated by the competitive examinations that guard the gates to secondary and tertiary levels of education [7].

Strategic planning is hoped to improve their quality because quality tools are used to improve processes. Thus, strategic planning and continuous quality improvement can be manifested in: improved teaching and learning, guidance and counseling; infrastructure including laboratories, electricity, internet connectivity, water and sanitary facilities, favorable environment for learning; teacher support system; responsible stewardship of resources, professional collaboration \& preparing students for success beyond school [8].

\section{Strategic Plans for Educational Institutions}

Unlike the private sector, the notion of quality products, markets, activity timelines and customer service are not common terms in many public schools. Strategic plans for educational institutions should contain information on enrollment goals and management initiatives; student population and their categories; academic programs and changes in pedagogy; supporting facilities and student affairs; staffing levels, training and development needs for both academia and non-academic staff [9]. In addition, strategic planning requires time, money and effort. It calls for preparatory sessions in form of either short or concentrated long meetings and later revision of plans based on feedback. The University of Wisconsin strategic plan took several months to formulate. However, long timelines are generally not advisable because people get exhausted and slack momentum. It's also worth noting that strategic planning is a costly undertaking. A good planning process requires money to facilitate the activities in terms of refreshments, travel cost, facilitators and audio visual equipment among others. Deliberate decisions are made to focus or refocus on the organization, which means something has to be done away with or at the very least something has to change. To succeed in strategic planning, there must be bold approach that breaks barriers and articulates new strategies to propel the organization to its vision.

Participation in strategic planning process should be paramount to ensure it's driven by information from both 
internal and external stakeholders regarding their needs, expectations and requirements as foundation for the planning. Employees in the organization are likely to support implementation of educational initiatives like new curriculum and changes in pedagogy if they are involved right from the plan formulation. External stakeholders on the other hand are traditionally known for advisory roles and provision of resources. Thus, their involvement essentially laid groundwork for continuing support and participation that makes implementation feasible. Involvement of stakeholders reflects personal and collective commitment of staff because they can identify with the process and its purpose.

Strategic planning works well as a tool for systematic quality improvement that enables stakeholders to increasingly contribute to the school objectives and contribute to their achievement. In his experience committees were established to; develop a systematic process to evaluate, measure and drive continuous improvement of staff wellbeing and motivation; identify private grant funds; benchmark with other organizations as well as develop a system for facilities establishment and maintenance [10]. In formulating strategic plans, the groups strive for consensus beginning with individual opinions, then small groups to the whole. It's in this process that members commit to support the results even if they don't agree with everything in the plan.

School strategic plans provide a base for the institution to progress, efficient and effective allocation of resources and create more relevant structures to improve performance. The planning process is turned out to be more beneficial than the plan because it provides a path which allows community to work together to accomplish set goals. If the process of strategic planning is well handled, it would give the school management an opportunity to invite stakeholders who in return provide material and moral support in the development agenda of the school. In the process, the stakeholders gain grounds to demand for transparency in the use of school resources. The school management on the other hand is obliged to allocate resources equitably, with clear responsibilities and open lines of communication to enhance feedback.

\section{Formulating Strategic Plans for Educational Institutions}

At the initial stage, planning a committee is established with representatives of key stakeholders. The committee engages in information gathering through consultations, benchmarking, literature review, one on one discussion and workshops. The consultant should collect pertinent information, analyze and review it jointly with the liaison team to provide an adequately informed basis for developing the components of the strategic plan. At this stage, it's important to consider if the organization is ready for long term plans. Perhaps it's better to do one year plan if the organization is not stable. In Kenya, about $70 \%$ of secondary schools were observed to have formulated strategic plans which covered between 3-5 years. However, many head teachers had not implemented the plans due to constraints like lack of adequate resources and technicalities in translating plans to actions. Consequently, majority of schools have strategic planning blue print as a formality to meet policy requirement but not to guide their operations. Furthermore, most of the schools reported had hired experts to formulate strategic plans for them and were only aware of scanty details of their content [11].

It is imperative to consider the process and establish responsibilities for members of planning committee. These may include representatives of staff (technical and support), funding organizations, sister organizations, and perhaps former leaders of the organization especially to analyze the mission, vision and core values in order to gain deeper understanding of the organization and integrate new directions the school may want to embrace. The mission is the stated purpose of the organization existence. Public statement of what the school promises to its customers and the society at large. Mission statement is the reason of being or the purpose of existence. It describes the products and services the organization offers and how uniquely they are offered. It provides focus for the school operations while the vision is the big picture of where the school wants to be in the future. A vision should energize people to walk the journey of plan implementation with focus and determination. Core values are the norms and beliefs that institutions strongly subscribe to as the guiding principles in their operations [12]. Once the vision and mission are clearly identified, the planning team must engage in an environmental scan so as to analyze the external and internal environment of the organization.

Environmental scan looks at both the internal (factors that school management has control over) assessing organizational strengths and weaknesses and external factors (factors that school management has no control over e.g. economic, social, demographic, political, legal, technological). This helps to identify opportunities and threats. External environment refers to the broad environment in which the organization operates. Environmental scan sometimes calls for needs assessment through interviews, focus group discussions, and email survey etc. In relation to internal environment organization, performance is assessed including financial and human resource (inputs), operating methods or processes and outputs. This helps to identify critical success factors for the school such as relationship with target community, teaching learning resources, academic programs, governing structure, and staff skills among others. At this stage, the management and staff provide useful insights that guide the remaining steps. Various models can be adopted including SWOT analysis PESTEL and ABCDE models. However, this models yield different results in different environments. This paper proposes a model for strategic planning in educational institutions as shown in Figure 1. 


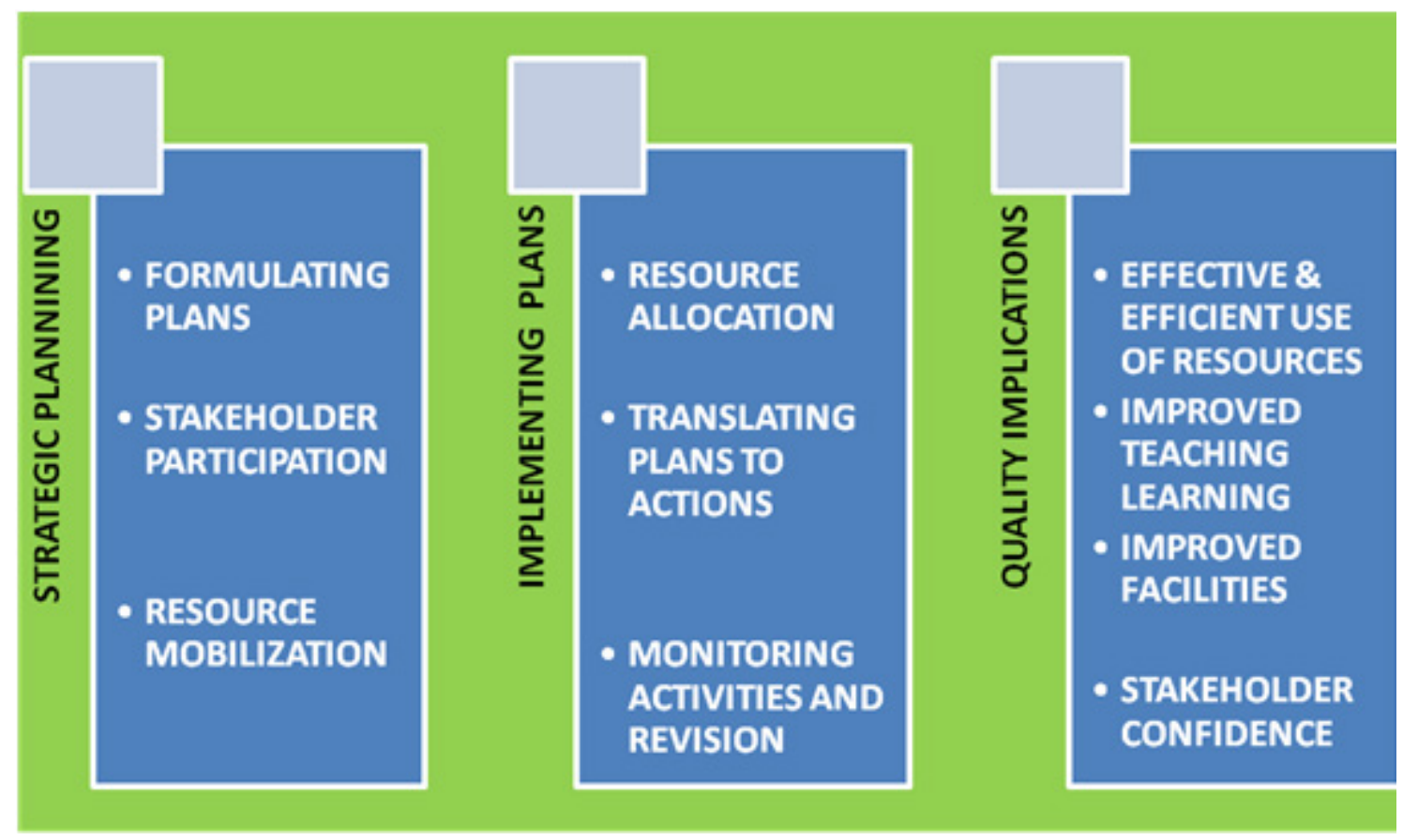

Figure 1. Strategic Planning for Quality Education

From the diagram, strategic planning is a process and not one time thing. Its success lies in how the process is handled right from the planning stage and where the plan is drawn and documented. At this stage, stakeholder are consulted to give their views on mission, vision and core values the organization should embrace to suit the emerging issues. Together, they examine the current situation of the organization; the desired direction to take it and strategies to help it get there (Strategic Planning). This helps stakeholders to own the plan and become enthusiastic about implementation. They are ready to take various responsibilities, commit their resources and approach potential partners on behalf of the School Board of Management. This collaboration goes a long way in mobilizing sufficient resources for implementing the strategic plan. Resources both material and human are pivotal to successful implementation of the plan. Strategic Actions are taken giving rise to programs, organization development and improved governance. During implementation, activities are monitored through collecting feedback and corrective measures are taken to continuously improve the quality of education. Introduction of monitoring and evaluation brings about the culture of accountability and transparency in management of resources. Efficient and Effective use of resources manifest in improving teaching and learning and expansion of school facilities which promote confidence among stakeholders to continue supporting the organization. In essence, quality education is an outcome of strategic planning in the education sector. All educational organizations should adopt strategic planning to enhance the quality of education and continuously improve performance amidst limited resources.

\section{From Strategic Plan to Strategy Implementation}

Implementing a strategic plan requires clear documentation of directions or actions and ability to turn the strategic thought into actions indicating who is responsible for each action, date by which the action is expected to be complete and measures to assess the action. A standing committee with representatives of key stakeholders especially from functional areas of the organization with working skills ensures there are participants who will be involved in implementation and assessment [13]. This is essential to ensure planning is being monitored to keep it on track and remain responsive to changing needs. When such groups are represented in the formulation, they understand how planning process works and supports its implementation. This calls for identifying individuals and teams who have the motivation to make the plan a reality [9].

A great deal of work goes into crafting a convincing strategic plan and now comes the tougher part of making it happen. ACRA White paper outlined elements of a successful plan as stakeholders representatives to enable groups get information and bring feedback to enrich the process, reliance on empirical data for decision making with regard to customer needs by evaluating existing services and preparation for the participants to understand change and embrace paradigm shift by engaging resource people to engage them on futuristic discourse to open their mind. It's a structured process with sequenced activities that encourage intellectual fusion for superior results that go beyond what any individual can generate alone by all means [14]. Of greater importance are the successful use of the plan, the payoff in its application, execution and implementation. 
However, strategic plan is futile if it is not used because planners are likely to grow frustrated seeing their product sit on the shelves.

\section{Challenges Associated with Strategic Planning in Education}

For a long time, an attempt to design an assessment based change in the education sector has been frustrating and ineffective most often in many developing countries. After all, schools are perceived as government institutions and they offer services that are always in great demand regardless of their quality levels. In Kenya, public schools management do not perceive themselves as serving customers because the masses are desperate to receive this essential service. In the past, school management expected schools to grow naturally by receiving funds from the government year in year out while at the post-secondary level strategic planning was viewed as a tool to articulate institutional mission and vision to help prioritize resources and promote organizations' focus. At the onset, some school strategic plans just described the organization "self-documents" that sowed a seed of discontent and plans were not implemented in many instances. Many organizations began to display their mission and vision even if they were not reflected in their practices. This did not change their ways of doing things as the mission and vision were perceived to be just another requirement by the authorities.

Planning is more complex and there were no institutions that would boast of staff with enough experience to lead the process without external guidance. In addition, instances of wrong personnel assigned to lead the process caused stumbles, misdirection or even political problems that slowed or stalled the process. Some started the process just to hit a wall and call in a consultant to clear the mess and educate the team on what the plan should be. However, it's important to evaluate the capacity of the consultant to lead the planning process and see it to implementation. The plan needs to be flexible and self-sustaining by matching the culture and priorities of the institution [13]. This is enhanced by regular updates such as midyear, end year and status reports which give the institution opportunities to keep implementation on schedule and allow it to adjust plans to accommodate changes in the environment. Third and fourth assessment occurs at the end of the plan period when expiring plan is reviewed and planning process is improved.

Long range planning was practiced in many private schools which were mission driven, had long-term objectives and short term actions needed to be efficiently integrated to meet changing needs of the market and public schools never aspired to emulate them [13]. In Kenya, strategic planning has coincided with difficulties in public schools as enrolments began to raise, students demographics started to change and funding by the government remained constant against deteriorating infrastructure. At this point, strategic planning seems to be one of the solutions for developing proactive stance in an environment of changing demands and declining resources. Fee paying should be considered along with safeguards to subsidize access for those from low income families. This would lead to increased enrolments at no additional public cost as net benefit [15]. The task is now for the school management and stakeholders to identify management approaches that will succeed in improving participation, learner achievement and quality in particular circumstances of the school category, region and customer needs.

\section{Implications of Strategic Planning}

In essence, strategic planning process help leaders to think and act strategically, develop effective strategies, clarify future directions for the organization, establish priorities and establish teamwork to improve performance. Consequently, it's viewed as critical in times of change in school leadership by keeping the organization focused yet flexible to meet the dynamics of the modern society. In Kenya, for example as in many democratic systems, there are frequent changes in leadership where leadership tenure can be as short as five years [9]. In such circumstances, organizational stability is enhanced because established committees still serve as the organizational memory in focusing on the future.

In addition, strategic planning provides understanding on how schools work, gives insights on how finances are spent, identifies needs of stakeholders and gives an opportunity to set specific data driven priorities. Also change in the way of people work is manifested and it's a more democratic way of planning. Involvement of stakeholders especially at implementation stage creates synergy. It brings on board partners from private sector to finance vocational programmes and general infrastructure. Learners' participation is of great importance as their views can help the management in establishment of priority areas in organizational development. As a result, the achievement of strategic planning's performance and excellence in academics, arts and aesthetics making it worth the effort.

Strategic plans allow school management to articulate clear goals and objectives for improving teaching and learning. It's also believed to enhance a strong working relationship with the community, and elect officials who support education making implementation smooth. Evidently, strategic planning entails reforming relationship of accountability among various stakeholders and participants in the education sector so that responsibilities are clear, measured, monitored and supported. It is accompanied by clear feedback cycle between financiers, strategy implementers and beneficiaries [14]. More so, strategic planning should not be initiated in an organization that is experiencing crisis as the energy and resources could be used for more urgent needs to salvage the organization rather than advance planning.

The benefits of strategic planning require bold yet 
effective information gathering system and exploration of alternatives and emphasis on future implications of present decisions. To succeed the plan should: clarify organizational priorities; be anchored in the organizations 'culture; be a collective participatory process; a transparent and embraced by all; clarify the purpose with realistic goals [6].

ECRA White paper outlined benefits of strategic planning as: helping to create a consensus on where an organization is going; forming basis of communicating to others in order to inform, motivate and involve. This ensures effective use of resources by allocating resources to the key priority areas and it serves as a framework for decisions or for securing support. It further enables monitoring of results and being accountable, assists in benchmarking, performance monitoring and evaluation and stimulates change and becomes building block for next plan period.

\section{Conclusions}

Strategic planning can be one of the most effective tools for driving school reforms in education sector if the process involves key stakeholders. In order to make strategic planning to be successful, the planning team needs to possess requisite management skills to overseeing the process to success, allocating specific responsibilities to key stakeholders, and availing necessary resources coupled with effective communication to enhance meeting set timelines. However, it can only succeed if school management is willing to be honest and transparent in revitalizing their institutions and committing to creating their future and when effectively implemented strategic plans give leaders in the education sector a very focused and clear process of leading change initiatives for improved organizational performance and growth in desired direction.

\section{REFERENCES}

[1] Hakijamii (5 ${ }^{\text {th }}$ April , 2010). Kenya Education Rights Update Issue Education Financing Pub- Nairobi Kenya.

[2] Institute of Economic Affairs. (2013). Budget Guide: Budget 2013/2014 the Onset of the Huddles Ahead. Nairobi.
Republic of Kenya.

[3] Marlaine E., Lock head and Adnaan, M. (1991). Improving Primary Education in Developing Countries. Washington: Oxford University Press

[4] Mundavi - Moyo, J. and Keith, M. (2001). Financing Secondary Education: Access, Equity and Efficiency Revisited. Paris: IIEP.

[5] World Bank (2011). Learning for All: Investing in People's Knowledge \& Skills to Promote Development. Washington DC.

[6] Auburn School District 2013-2016 Strategic Plan Committee. Website: www.auburn.wednet.edu.. Retrieved 2015-03-21.

[7] UNESCO. (1985). Reflections on the Future Development of education. Paris.

[8] Association for the Development of Education in Africa ADEA. (December, 2003). Quality of Secondary Education in Africa (SEIA) Grand Baie, Mauritius, 3-6, 2003 by Jacob Bregman and Karen Bryner. Web site: www.ADEAnet.org Retrieved 2015-03-17.

[9] Katheren, P. (November, 2003). Strategic Planning in the University: University of Wisconsin System Board at www.QUALITY.WISC.EDU

[10] Bradley, J. (2004). Planning for Quality in Education K-12 QED News Vol. IX, No. 4 Winter/Spring.

[11] Mwangi, K. (2012). Challenges facing public Secondary School Managers in the Implementation of Strategic Plans in Gatundu North District Kiambu County. Med Project Kenyatta University. Nairobi

[12] Jasporro, R. (2015). Strategic Planning: Is it Worth the Effort. Johnson \& Wales University. Retrieved from file://c:/users/user/Desktop/strategicplanning.html February $10,2015$.

[13] Hinton, K., (2012). A Practical Guide to Strategic Planning in Higher Education society for Colleges and Universities Planning. Retrieved from sepguideonplanningpdf. website: www.scup.org Retrieved 2015-03-21.

[14] ECRA White paper. Creating the Future: Strategic Planning for schools pdf Retrieved January 2015.

[15] Hough, J. (1993). Financial Management in Education. UNESCO: University of Loghborough

[16] World Bank (2000). Higher Education in Developing Countries: Peril and Promise. Washington DC. 